\title{
REVIEW
}

\section{Desquamative interstitial pneumonia: an analytic review with an emphasis} on aetiology

\author{
Benoît Godbert*, Marie-Pierre Wissler" and Jean-Michel Vignaud ${ }^{\#}$
}

ABSTRACT: Desquamative interstitial pneumonia (DIP) is characterised by the accumulation of numerous pigmented macrophages within most of the distal airspace of the lung and, sometimes, the presence of giant cells. Diagnosis of DIP is not easy and requires surgical lung biopsy. DIP is usually associated with tobacco smoke. However, the association between smoking and DIP is less robust than that with respiratory bronchiolitis with interstitial lung disease or pulmonary Langerhans' cell histiocytosis; approximately $10-42 \%$ of patients with DIP are nonsmokers. DIP can also occur in patients following exposure to certain inhaled toxins (occupational exposure) and drugs, and may occur in the context of certain viral illnesses and autoimmune diseases. In the context of DIP, occupational exposure should be systematically investigated.

KEYWORDS: Giant cell, interstitial lung disease, macrophages, occupational lung disease, surgical lung biopsy, tobacco

D esquamative interstitial pneumonia (DIP) was described by LIEBOW et al. [1] in 1965. Its name originated from the belief that the dominant histological feature was desquamation of epithelial cells [1, 2]; however, this is now recognised to be the accumulation of intra-alveolar macrophages, sometimes associated with giant cells [3]. Despite the inaccuracy of this term, the American Thoracic Society and European Respiratory Society have retained the term DIP, mainly because of this disease's rarity [4].

It is now fairly certain that DIP is very often associated with cigarette smoke and even with passive exposure. The incidence in smokers ranges from $58 \%$ to $91 \%[3,5,6]$; thus, many patients with DIP are cigarette smokers. However, DIP is more frequently seen in nonsmokers than respiratory bronchiolitis associated with interstitial lung disease (RB-ILD), and has also been observed in pneumoconiosis, rheumatological disease and some drug reactions [7-9]. Thus, DIP is not always associated with exposure to tobacco smoke: occupational exposure to other agents should also be considered to avoid disregarding an occupational aetiology. In this article, we systematically review DIP and, in particular, the association between occupational exposure and DIP.

\section{EPIDEMIOLOGICAL AND CLINICAL FEATURES}

The average age at onset of symptoms of DIP is between 40 and 60 years [1, 3, 5, 6]. Most studies note a predominance of male patients, i.e. a 2:1 ratio to females $[1,3,5,6]$. The most frequent presenting features of DIP are the onset of breathlessness during exercise and a persistent cough that is not always productive of sputum $[1,3,5,6]$. Chest pain and systemic symptoms, including weight loss and fatigue, can also be present $[1,3,5$, 10]. Haemoptysis is rarely described [1, 3]. Occasionally, DIP may be diagnosed in an asymptomatic individual $[3,5,6]$. Bibasilar endinspiratory crackles and cyanosis are frequently present, and clubbing is not rare $[1,3,5,6,10]$. Thus, DIP is classically characterised by an insidious onset of symptoms but may present as a fulminant or rapidly progressive disease [11-13]. The epidemiological and clinical features of DIP are summarised in table 1.

\section{PULMONARY FUNCTION TESTS}

Pulmonary restriction is usually absent or slight, although diffusion is impaired in most patients with DIP $[1,3,5,6]$. In the first description of DIP by LIEBOW et al. [1], total lung capacity was $<80 \%$ predicted in only two out of 10 patients; in a study by YOUSEM et al. [5] mean total lung
AFFILIATIONS

*CHU de Nancy, Pôle de spécialités médicales, Service de pneumologie, Nancy, and

${ }^{*} \mathrm{CHU}$ de Nancy, Pôle laboratoires, Service d'anatomo-pathologie,

Nancy, France.

\section{CORRESPONDENCE}

B. Godbert

Service de Pneumologie

Bâtiment Philippe Canton

Hôpitaux de Brabois-CHU de Nancy

Avenue de Bourgogne

54511 Vandoeuvre-les-Nancy cedex France

E-mail: benoit.godbert@hp-metz.fr

Received:

Sept 252012

Accepted after revision:

Oct 232012

PROVENANCE

Submitted article, peer reviewed.

European Respiratory Review Print ISSN 0905-9180 Online ISSN 1600-0617 


\begin{tabular}{|c|c|c|c|c|c|}
\hline & Liebow [1] & TuBbs [3] & Yousem [5] & Ryu [6] & Total \\
\hline Males/females n & $10 / 8$ & $17 / 9$ & $26 / 10$ & $11 / 12$ & $64 / 39$ \\
\hline $\begin{array}{l}\text { Age at onset years median } \\
\text { (interquartile range) }\end{array}$ & 45 (16-63) & $51(24-75)$ & $42(17-67)$ & 46 (26-69) & $46(16-75)$ \\
\hline $\begin{array}{l}\text { Mean smoking exposure } \\
\text { pack-years }(95 \% \mathrm{Cl})\end{array}$ & & $\geqslant 10$ & $36(10-71)$ & 31 (10-90) & \\
\hline $\begin{array}{l}\text { Occupational history, cases } \\
\text { exposed }\end{array}$ & $\begin{array}{c}1 \text { exposed to plastic } \\
\text { fumes and dusts } \\
2 \text { exposed to hairsprays }\end{array}$ & NS & NS & $\begin{array}{l}\text { No environmental } \\
\text { exposure or underlying } \\
\text { disease identified }\end{array}$ & \\
\hline \multicolumn{6}{|l|}{ Symptoms } \\
\hline Chest pain & 9/12 (75) & $1 / 26(4)$ & NS & 4/23 (17) & 14/61 (23) \\
\hline Haemoptysis & $1 / 18(5.5)$ & 2/26 (8) & NS & NS & $3 / 44(7)$ \\
\hline Asymptomatic & $0 / 18(0)$ & $1 / 26(4)$ & $5 / 34(15)$ & 1/23 (4) & $7 / 101(7)$ \\
\hline \multicolumn{6}{|l|}{ Physical signs } \\
\hline Cyanosis & $7 / 10(70)$ & 3/26 (11.5) & NS & NS & 10/36 (28) \\
\hline Crackles & $<50 \%$ & $17 / 26(65)$ & $5 / 9(56)$ & $13 / 23(57)$ & $35 / 58(60)$ \\
\hline Clubbing & $5 / 9(55.5)^{\#}$ & $12 / 26(46)$ & $15 / 36(42)^{\#}$ & $6 / 23(26)$ & $38 / 94(40)$ \\
\hline
\end{tabular}

Data are presented as n/N (\%), unless otherwise stated. NS: not specified. ${ }^{\#}$ : clubbing sometimes disappeared after steroid therapy.

capacity was $94 \%$ (range $43-133 \%$ ). At rest, as during exercise, gas exchange is mostly impaired because alveolar-arterial oxygen pressure is increased [1]. Indeed, in the description of DIP by LIEBOw et al. [1], systemic arterial saturation at rest was $<95 \%$ in eight out of 10 subjects and oxygen saturation diminished in all after mild exercise. In addition, the difference between alveolar-arterial oxygen pressure was elevated in all five patients in whom it was measured, ranging from 13 to $53 \mathrm{mmHg}$ [1]. In the same study, carbon monoxide diffusing capacity was tested in seven patients and was found to be sharply reduced in six [1]. In the study by YOUSEM et al. [5], mean carbon monoxide diffusing capacity was $45 \%$ pred (range $32-78 \%$ pred). Significant obstructive impairment (forced expiratory volume in $1 \mathrm{~s}$ (FEV1)/forced vital capacity $(\mathrm{FVC})<70 \%$ ) is uncommon in DIP and is probably attributable to coexistent chronic bronchitis [3]. Cor pulmonale is rare [14].

\section{BIOLOGICAL ANALYSES}

Biological analyses of DIP (blood cell count, sedimentation rate, renal function, liver function, immunological analysis, etc.) have been generally unrewarding. Where data are presented in published studies, they do not reveal specific significant abnormalities for DIP [1], although LIEBOw et al. [1] found polycythaemia in six out of 16 cases caused by respiratory insufficiency. In general, levels of C-reactive protein are not described. Serum lysozyme level has been reported to be elevated some of the time [15]. Bronchoalveolar lavage fluid invariably contains increased numbers of alveolar macrophages, a large proportion of which have granules of "smoker's pigment" consisting of intracellular yellow, golden-brown or black particles [16]. Increased numbers of neutrophils, eosinophils and lymphocytes have also been found [17-19], but these findings are not very specific.

\section{RADIOLOGICAL FEATURES}

The appearance of chest radiographs is often normal and any abnormalities tend to be limited and nonspecific $[1,4]$. Reported radiographic signs of DIP include widespread, patchy ground-glass opacification, with a greater predilection for the lower-lung zone and, sometimes, peripheral predominance $[1,4]$. The ground-glass opacification sometimes has a granular or nodular texture [20]. Because of the low prevalence of DIP, its identification by high-resolution computed tomography (HRCT) has been only characterised in one small series $(n=22)$ [21]. Ground-glass attenuation was present on the computed tomograms of all of the 22 cases and was bilateral and moderately symmetric in $\geqslant=50 \%$ of these cases. It had a lower-zone distribution in the majority (73\%) of cases, a peripheral distribution in $59 \%$ of cases and was patchy in $23 \%$ (figs 1 and 2). Distribution was diffuse and uniform in 18\%. Irregular and linear opacities and reticular patterns were frequent (59\%) but were limited in extent and usually confined to the base of lungs. They were associated with anatomical distortion, traction bronchiectasis and small peripheral cystic spaces, which are believed to represent dilated bronchioles and alveolar ducts. Honeycombing was seen in less than one-third of cases, and was usually peripheral and limited in extent [21]. KAWABATA et al. [19] suggest that DIP may progress to lung fibrosis. Indeed, long-term follow-up of 14 patients (mean 

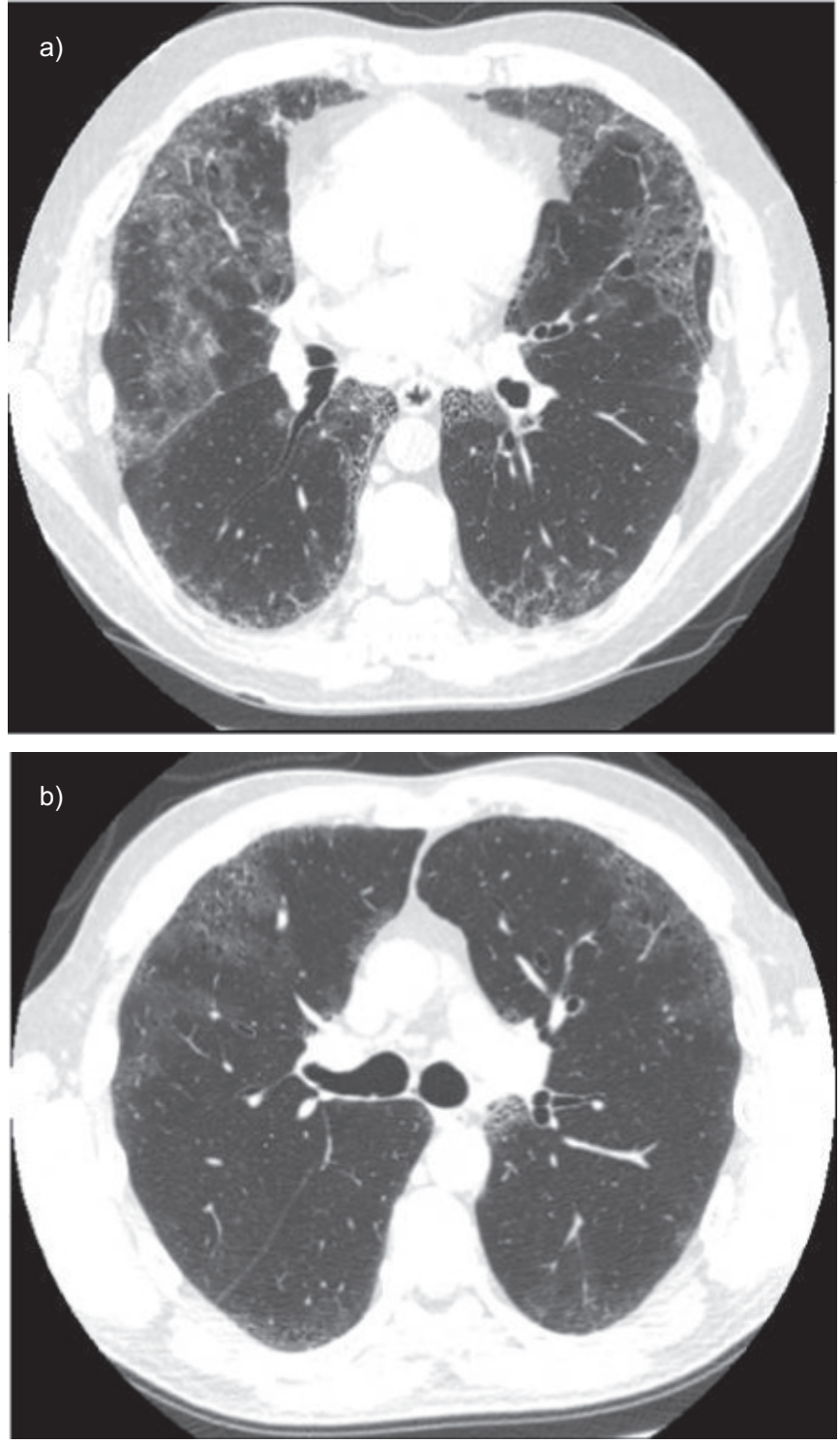

FIGURE 1. Example of thin parenchymal section computed tomography findings in desquamative interstitial pneumonia: patchy ground-glass attenuation with a peripheral bilateral and almost symmetric distribution, and irregular and linear opacities.

125 months) by HRCT showed the development of new thinwalled cysts and honeycombing in five patients [19].

In the absence of contraindications, the appearance of extensive ground-glass attenuation on HRCT and the bronchoalveolar lavage are both nonspecific, and according to the guidelines of the American Thoracic Society/European Respiratory Society and the British Thoracic Society, a surgical biopsy is advised in patients with suspected idiopathic interstitial pneumonia who does not show classic clinical and HRCT images of usual interstitial pneumonia [4, 22]. Indeed, the subtle distinction between macrophage distribution and intensity, and the patterns of interstitial fibrosis across the secondary lobule, upon which the diagnoses of RB-ILD and DIP are predicated, cannot be achieved in the limited samples provided by a transbronchial biopsy or core-needle biopsy. The presence of DIP-like reactions around a variety of spaces that occupy pulmonary lesions and of some diffuse pulmonary disorders further limit the diagnostic application of small-tissue biopsies: this mandates close radiographic correlation with findings from a surgical lung biopsy to avoid over-diagnosis of DIP or RB-ILD [23, 24]. Thus, the diagnosis of DIP requires a surgical lung biopsy (thoracoscopic or open-lung procedure).

\section{HISTOLOGICAL FEATURES}

Histological features were initially described by LiEBOw et al. [1]

\section{Gross features}

Surgeons have described the DIP lung as stiff, indurated and somewhat nodular in some cases. In some parts, a coarser porosity than usual gives the scattered foci a finely honeycombed appearance, and the tissue completely lacks the soft, spongy characteristics of a normal lung [1].

\section{Histology}

DIP's main feature is the presence of large numbers of macrophages within alveoli that have a diffuse distribution throughout the pulmonary acini $[4,5,24]$. These macrophages have abundant eosinophilic cytoplasm and often contain a finely granular light-brown pigment [5]. The presence of a few multinucleated giant cells is common [1,3]. The alveolar architecture is generally well maintained, although there is mild chronic inflammatory infiltrate within the interstitium. A moderate number of eosinophils may also be seen. Lymphoid aggregates may be present (fig. 2a-c) [1, 3, 4]. Interstitial fibrosis is usually mild. If present, loss of architecture and cystic airspace formation appear closer to emphysema than to the honeycomb change seen in usual interstitial pneumonia [25].

Epidemiological studies suggest that $\sim 58-91 \%$ of cases occur in smokers and, in this context, DIP may be regarded as an excessive response to tobacco smoke. With the recognition of RB-ILD, DIP has come under scrutiny and many believe that RB-ILD and DIP comprise points along a spectrum. The histological findings for RB-ILD are an exaggerated inflammatory reaction with a marked increase in macrophages in and around respiratory bronchioles and minor interstitial thickening (fig. 2d-f). In theory, DIP shows uniform diffuse airspace filling by macrophages, with mild interstitial thickening and a mild chronic inflammatory infiltrate. In practice, the changes may not be entirely uniform. In given cases, one can find fields that qualify as RB-ILD and fields that qualify as DIP. However, although RB-ILD is a disease of smokers, there are several agents that can cause a DIP-like reaction, such as dust inhalation [26, 27], drug reactions [28] and inborn errors of metabolism like in Gaucher's disease [29]. DIP is usually distinguishable from usual interstitial pneumonia, organising pneumonia, lymphoid interstitial pneumonia and diffuse alveolar damage because the significant accumulation of macrophages is not seen and other histopathological features are absent but, in rare cases, an overlap exists between DIP and nonspecific interstitial pneumonia. Indeed, JANKOWICH et al. [30] described a series of 10 patients with combined fibrosis and emphysema, in which two patients demonstrated a pattern of interstitial lung disease, on biopsy, characterised by intraalveolar macrophage accumulation in association with marked alveolar septal fibrosis, consistent with a variant form of DIP with extensive fibrosis. Furthermore, KAWABATA et al. [19] 

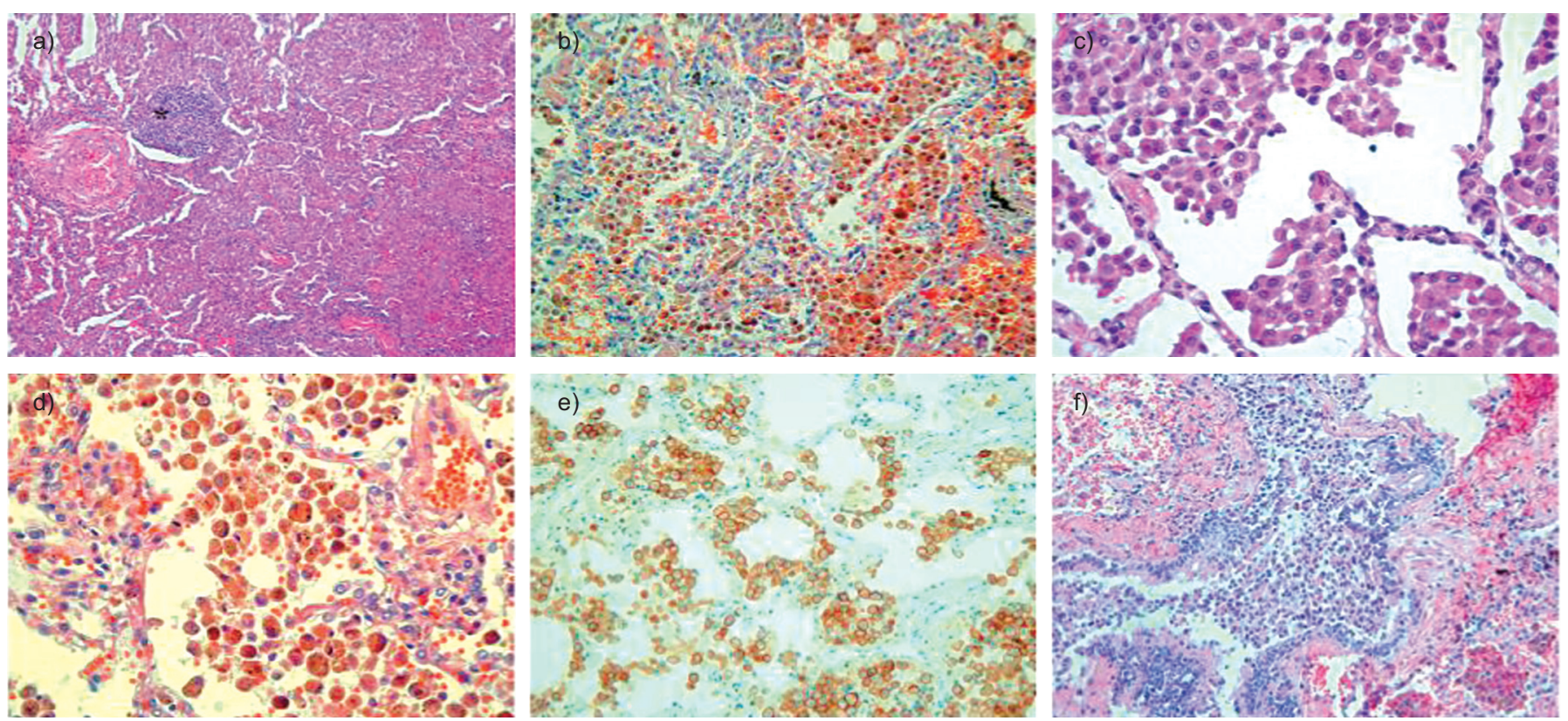

FIGURE 2. a-c) This lung biopsy from a 55-year-old male patient, who was a nonsmoker, shows a typical desquamative interstitial pneumonia pattern. Tissue sections show a) diffuse involvement of the lung by intense macrophage accumulations within almost all of the distal airspace, b) without significant thickening of alveolar septa and sparse inflammatory infiltrate $(*)$. Macrophages do not contain dusty pigment. c) Immunohistochemical analysis with CD163 antibody shows the macrophage nature of the cells. d-f) Lung biopsy from a 66-year-old female, who was a heavy smoker, showing a respiratory bronchiolitis/interstitial lung disease pattern. d) Macrophage accumulation is diffuse but predominantly peribronchiolar and f) in respiratory bronchioles. Alveolar septa are slightly thickened. e) The cytoplasm of most macrophages contains an abundant dust-brown pigment.

suggest that DIP may progress to lung fibrosis (radiological data).

Giant-cell interstitial pneumonia is DIP-like with more numerous multinucleated giant cells. It is associated with occupational exposure to hard metal dust; thus, occupational exposure should be explored and systematic mineralogical analysis of a biopsy sample is warranted though is not absolutely necessary for diagnosis.

\section{AETIOLOGIES OF DIP}

Radiological support for smoking-related interstitial lung disease was initially provided by WeISS [31, 32] and others, who found that a mild degree of "diffuse pulmonary fibrosis" was three times more common in smokers than in nonsmokers. Most authors have almost invariably associated DIP with smoking $[4,5,21,23,33-35]$, although DIP is sometimes present in nonsmokers. In the series of CRAIG et al. [9], $40 \%$ of 20 patients were lifelong nonsmokers, yet in an older series of TUBBS et al. [3], $42 \%$ of 26 patients had no history of cigarette smoking. These findings suggest other aetiologies for DIP: environmental exposure to inorganic particles is a recognised cause of DIP [1, 8]. Thus, Abraham and HertzberG [8] conducted a study in 1981 on 62 cases of biopsy specimenproven cases of DIP. The biopsies were explored for inorganic particles by scanning electron microscopy and all inorganic particles were individually analysed using energy-dispersive X-ray analysis. Of the 17 cases quantitatively analysed, there were mean \pm SEM $5.8 \times 10^{7} \pm 1.1 \times 10^{7}$ particles per $\mathrm{cm}^{3}$ and $0.8 \times 10^{6} \pm 0.63 \times 10^{6}$ particles per $\mathrm{cm}^{3}$ in controls $(\mathrm{n}=5)$ $(\mathrm{p}<0.001)$ [8]. Among the 17 patients, seven had an occupational history compatible with exposure to inorganic particles, and high concentrations of inorganic particles were found in their biopsies [8]. Thus, these authors showed that $\sim 75 \%$ (of those with an available environmental history) had a history of dust or fume exposure, and that specific types of particle exposure were documented in $92 \%$ of cases. These findings show an association between DIP and exposure to some particles, suggesting an aetiological relationship [8].

Among 20 patients in a study by CRAIG et al. [9], two of the eight nonsmokers and one patient in the smoker group had been exposed to occupational dust as fire-extinguisher powder, diesel fumes, and beryllium and copper dust, respectively. In addition, MooN et al. [10] described a case of DIP in a nonsmoking patient who was exposed to solder fumes at work. However, there is no proof of a link between this occupational exposure and the occurrence of DIP; however, in light of the study by ABrAHAm and HerTZBerg [8], we can suggest that this link is highly probable.

Another occupational cause of DIP could be exposure to nylon filaments in textile works. Indeed, LOUGHEED et al. [36] described a series of five employees from a small textile plant that employed 88 workers. Two of these five patients were exsmokers and three were never-smokers. The plant manufactured upholstery fabric by gluing finely chopped nylon filament ("flock") to cotton/polyester fabric using a latex adhesive. Lung biopsy samples demonstrated DIP associated with diffuse alveolar damage. The unusual clustering of these cases within a small textile plant suggests a link with the occupational environment [36]. The authors of this study suggested a potential role for mycotoxins inhaled from the work environment (aflatoxins from Fusarium spp. cultured 
from specimens taken from the work environment) [37]. It is reported that aflatoxins may be toxic to the lungs [36-41]; however, only one of these studies described interstitial lung disease related to aflatoxin toxicity [36-42]. Thus, the imputability of aflatoxin remains very uncertain.

Another case of DIP has been described in a 38-year-old male textile worker [42]. This was a biopsy specimen-proven case, with severe restrictive syndrome: FEV1 and FVC were 55\% predicted, and FEV1/FVC was $99 \%$. The patient was a heavy smoker (50 pack-years) but after remaining off work for 5 weeks and without changing his smoking practices he felt somewhat better, and his FEV1 and FVC increased substantially to $84 \%$ pred without any other treatment. This suggests the probable role of toxins within his workplace [42]. Thus, DIP, in some cases, could be an occupational disease of textile workers.

Finally, DIP has been described in tungsten carbide production in biopsy specimens, as reviewed by LIEBOW and CARRINGTON [2].

Thus, there is a strong hypothesis that DIP can be caused by occupational exposure. We suggest that this should be systematically explored, and think that mineralogical analysis of biopsy samples is necessary when a case of occupationassociated DIP (exposure to inorganic dust) is suspected.

In addition, DIP has been associated with connective tissue disease [43, 44], rheumatoid arthritis [45], drugs such as sirolimus [46], infection [47-49], and users of large amounts of marijuana [50]. All known causes of DIP other than tobacco smoking are summarised in table 2.

\section{TREATMENT, RESPONSE TO TREATMENT AND PROGNOSIS}

Smoking cessation is probably an important and indispensable component in the management of patients with DIP, but the influence of smoking cessation on the clinical course has not been delineated.

Patients treated for DIP usually receive long-term corticosteroid therapy $[1,5,50]$. With this treatment, most patients remain stable or improve, and complete recovery is possible $[5,50]$; however, without treatment, $\sim 60 \%$ of patients with DIP suffer clinical deterioration [51]. In contrast, CARRINGTON et al. [51] observed spontaneous improvement without treatment in $\sim 20 \%$ of 32 patients, although whether improvement was related to smoking cessation is unclear. The role of cytotoxic and other immunosuppressive agents remains undefined but successful use of these agents has been described [52].

In occupation-associated DIP, cessation of exposure is necessary. Indeed, in the series of five patients studied by LOUGHEED et al. [36], all patients left the workplace, and only two of the five patients returned to work and both experienced a relapse. Two patients improved upon leaving the workplace and did not required steroid therapy whereas a clinical response to steroids was slow in the three other cases: steroid therapy was finally stopped after a mean of 17 months of therapy. Three of the five patients had chronic respiratory insufficiency and two remained oxygen dependent after exertion. Thus, steroid therapy was not very efficient in these cases [36].

KNYAZHITSKIY et al. [53] suggest a possible role for macrolide antibiotics in patients with DIP refractory to steroid therapy. They described the first case of DIP showing a rapid and dramatic response to treatment, in all clinical and radiographic parameters, with clarithromycin.

Transplantation is indicated for terminal respiratory insufficiency but recurrence in the transplanted lung has been reported $[54,55]$. Survival from DIP is evaluated to be between $68 \%$ and $94 \%[1,4-6]$.

\section{CONCLUSION}

DIP is usually associated with exposure to tobacco smoke but is sometimes present in nonsmokers, which strongly suggests occupation-associated DIP. Thus, occupational exposure of infectious or iatrogenic origins and connective tissue disease should be systematically explored.

Little is known about the differences between occupationassociated DIP, smoke-related DIP and idiopathic DIP. We found only one study that focused on the clinical differences between smokers and nonsmokers with DIP: the authors were

TABLE 2 All causes implicated in desquamative interstitial pneumonia (DIP), other than tobacco smoking
Causes
Ref.
Comments

$\begin{array}{lc}\begin{array}{l}\text { Occupational exposure to } \\ \text { inorganic particles }\end{array} & {[1,28-10]} \\ \text { Exposure to mycotoxins } & {[37-43]} \\ \text { Connective tissue diseases } & {[44,45]} \\ \text { Rheumatoid arthritis } & {[46]} \\ \text { Sirolimus } & {[47]} \\ \text { Infection } & {[48-50]}\end{array}$

[48-50]
Nature of particles: $\mathrm{Si}, \mathrm{Mg}, \mathrm{Ti}, \mathrm{Fe}, \mathrm{Ni}, \mathrm{Pb}, \mathrm{Cr}, \mathrm{Au}, \mathrm{Ag}, \mathrm{Al}, \mathrm{K}, \mathrm{Ti}, \mathrm{BaS}, \mathrm{Be}, \mathrm{Cu}$

Occupation: tool grinder, arc polisher, tyre manufacturing worker, plastic machinist, Al aro welder, worker exposed to fire-extinguisher powder, diesel fumes Occupational exposure to aflatoxin (textile worker)

DIP following concurrent CMV and Aspergillus pneumonias in a renal transplant recipient (who did not receive sirolimus)

Association of DIP and HCV infection

Association of DIP and CMV infection in a baby 
unable to identify any clinical differences [12]. Further multicentric observational studies with greater numbers of patients are warranted to search for clinical, biological, radiological and histological characteristic differences between occupationassociated DIP, smoke-related DIP and idiopathic DIP, if these exist. Detailed and specific exploration of possible occupational exposure and smoking history (including exposure to passive smokers) and systematic mineralogical analyses of biopsy samples are needed.

\section{STATEMENT OF INTEREST}

None declared.

\section{REFERENCES}

1 Liebow AA, Steer A, Billingsley JG. Desquamative interstitial pneumonia. Am J Med 1965; 39: 369-404.

2 Liebow AA, Carrington CB. The interstitial pneumonias. In: Simon M, Potchen EJ, LeMay M, eds. Frontiers of pulmonary radiology. 1st Edn. New York, Grune and Stratton, 1969; pp. 102-141.

3 Tubbs RR, Benjamin SP, Reich NE, et al. Desquamative interstitial pneumonitis. Cellular phase of fibrosing alveolitis. Chest 1977; 72: 159-165.

4 American Thoracic Society., European Respiratory Society. International multidisciplinary consensus. Classification of the idiopathic interstitial pneumonias. Am J Respir Crit Care Med 2002; 165: 277-304.

5 Yousem SA, Colby TV, Gaensler EA. Respiratory bronchiolitisassociated interstitial lung disease and its relationship to desquamative interstitial pneumonia. Mayo Clin Proc 1989; 64: 1373-1380.

6 Ryu JH, Myers JL, Capizzi SA, et al. Desquamative interstitial pneumonia and respiratory bronchiolitis-associated interstitial lung disease. Chest 2005; 127: 178-184.

7 Corrin B, Price AB. Electron microscopic studies in desquamative interstitial pneumonia associated with asbestos. Thorax 1972; 27: 324-331.

8 Abraham JL, Hertzberg MA. Inorganic particles associated with desquamative interstitial pneumonia. Chest 1981; 80: 67-70.

9 Craig JP, Wells AU, Doffman S, et al. Desquamative interstitial pneumonia, respiratory bronchiolitis and their relationship to smoking. Histopathol 2004; 45: 275-282.

10 Moon J, du Bois RM, Colby TV, et al. Clinical significance of respiratory bronchiolitis on open lung biopsy and its relationship to smoking-related interstitial lung disease. Thorax 1999; 54: 1009-1014.

11 Flusser G, Gurman G, Zirkin H, et al. Desquamative interstitial pneumonitis causing acute respiratory failure, responsive only to immunosuppressants. Respiration 1991; 58: 324-326.

12 Gould TH, Buist MD, Meredith D, et al. Fulminant desquamative interstitial pneumonia. Anaesth Intens Care 1998; 26: 677-679.

13 Sigala I, Kalomenidis I, Malagari K, et al. Dry cough and dyspnoea rapidly increasing to respiratory failure in a male smoker. Eur Respir J 2005; 25: 1122-1125.

14 Gaensler EA, Goff AM, Prowse CM. Desquamative interstitial pneumonia. N Engl J Med 1966; 274: 113-128.

15 Davies G, Wells AU, du Bois RM. Respiratory bronchiolitis associated with interstitial lung disease and desquamative interstitial pneumonia. Clin Chest Med 2004; 25: 717-726.

16 Veeraraghavan S, Latsi PI, Wells AU, et al. Bronchoalveolar lavage findings in idiopathic non specific interstitial pneumonia. Eur Respir J 2003; 22: 239-244.

17 Kawabata Y, Takemura T, Hebisawa A, et al. Eosinophilia in bronchoalveolar lavage fluid and architectural destruction are features of desquamative interstitial pneumonia. Histopathology 2008; 52: 194-202.
18 Kawabata Y, Takemura T, Hebisawa A, et al. Desquamative interstitial pneumonia may progress to lung fibrosis as characterized radiologically. Respirology 2012; 17: 1214-1221.

19 Hidalgo A, Franquet T, Gimenez A, et al. Smoking-related interstitial lung diseases: radiologic-pathologic correlation. Eur Radiol 2006; 16: 2463-2470.

20 Hartmann TE, Primack SL, Swensen SJ, et al. Desquamative interstitial pneumonia: thin-section CT findings in 22 patients. Radiology 1993; 187: 787-790.

21 Wells AU, Hirani N. Interstitial lung disease guidelines: the British Thoracic Society in collaboration with the Thoracic Society of Australia and New Zealand and the Irish Thoracic Society. Thorax 2008; 63: Suppl. 5, v1-v58.

22 Bedrossian CW, Kuhn C 3rd, Luna MA, et al. Desquamative interstitial pneumonia-like reaction accompanying pulmonary lesion. Chest 1977; 72: 166-169.

23 Wall CP, Gaensler EA, Carrington $\mathrm{CB}$, et al. Comparison of transbronchial and open lung biopsies in chronic infiltrative lung diseases. Am Rev Respir Dis 1981; 123: 280-285.

24 Nicholson AG. Desquamative interstitial pneumonia. In: Tomashefski JF, ed. Dail and Hammar's Pulmonary Pathology. Berlin, Springer 2008; pp. 710-712.

25 Herbert A, Sterling G, Abraham J, et al. Desquamative interstitial pneumonia in an aluminium welder. Hum Pathol 1982; 13: 694-699.

26 Freed JA, Miller A, Gordon RE, et al. Desquamative interstitial pneumonia associated with chrysotile asbestos fibres. $\mathrm{Br}$ J Ind Med 1991; 48: 332-337.

27 Hamadeh MA, Atkinson J, Smith LJ. Sulfasalazine-induced pulmonary disease. Chest 1992; 10: 1033-1037.

28 Amir G, Ron N. Pulmonary pathology in Gaucher's disease. Hum Pathol 1999; 30: 666-670.

29 Jankowich MD, Polsky M, Klein M, et al. Heterogeneity in combined pulmonary fibrosis and emphysema. Respiration 2008; 75: 411-417.

30 Weiss W. Cigarette smoking and diffuse pulmonary fibrosis: a preliminary report. Arch Envrion Health 1967; 14: 564-568.

31 Weiss W. Cigarette smoking and diffuse pulmonary fibrosis. Am Rev Respir Dis 1969; 99: 67-72.

32 Patel RR, Ryu JH, Vassallo R. Cigarette smoking and diffuse lung disease. Drugs 2008; 68: 1511-1527.

33 Ryu JH, Colby TV, Hartman TE, et al. Smoking-related interstitial lung diseases: a concise review. Eur Respir J 2001; 17: 122-132.

34 Well AU, Nicholson AG, Hansell DM. Challenges in pulmonary fibrosis. A smoking induced diffuse interstitial lung disease. Thorax 2007; 62: 904-910.

35 Lougheed MD, Roos JO, Waddell WR, et al. Desquamative interstitial pneumonitis and diffuse alveolar damage in textile workers. Chest 1995; 108: 1196-1200.

36 Hayes RB, Van Nieuwenhuize JP, Raatgever JW, et al. Aflatoxin exposures in the industrial setting: an epidemiological study of mortality. Food Chem Toxicol 1984; 22: 39-43.

37 Emanuel DA, Wenzel FJ, Lawton BR. Pulmonary mycotoxicosis. Chest 1975; 67: 293-297.

38 Baxter CS, Wey HE, Burg WR. A prospective analysis of the potential risk associated with inhalation of aflatoxin contaminated grain dusts. Food Cosmet Toxicol 1981; 19: 765-769.

39 Marx JJ Jr, Arden-Jones MP, Treuhaft MW, et al. The pathogenic role of inhaled microbial material in pulmonary mycotoxicosis demonstrated in an animal model. Chest 1981; 80: 76S-80S.

40 Dvorackova I, Pichova V. Pulmonary interstitial fibrosis with evidence of aflatoxin B1 in lung tissue. J Toxicol Environ Health 1986; 18: 153-157.

41 Kern DG, Kuhn C 3rd, Wesley EE, et al. Flock worker's lung. Chest 2000; 117: 251-259.

42 Nicholson AG, Colby TV, Wells AU. Histopathological approach to patterns of interstitial pneumonia in patient with connective tissue disorders. Sarcoidosis Vasc Diffuse Lung Dis 2002; 19: 10-17.

43 Lamblin C, Begoin C, Selens T, et al. Interstitial lung disease in collagen vascular diseases. Eur Respir J 2001; 17: Suppl. 32, 69s-80s. 
44 Ishii $\mathrm{H}$, Iwata A, Sakamoto N, et al. Desquamative interstitial pneumonia (DIP) in a patient with rheumatoid arthritis: is DIP associated with auto-immune disorders ? Intern Med 2009; 48: 827-830.

45 Flores-Franco RA, Luevano-Flores E, Gaston-Ramirez C. Sirolimus associated desquamative interstitial pneumonia. Respiration 2007; 74: 237-238.

46 Sung SA, Ko GJ, Kim JY, et al. Desquamative interstitial pneumonia associated with concurrent cytomegalovirus and aspergillus pneumonia in a renal transplant recipient. Nephrol Dial Transplant 2005; 20: 635-638.

47 Iskandar SB, McKinney LA, Shah L, et al. Desquamative interstitial pneumonia and hepatitis $C$ virus infection : a rare association. South Med J 2004; 97: 890-893.

48 Schroten $\mathrm{H}$, Manz S, Kohler H, et al. Fatal desquamative interstitial pneumonia associated with proven CMV infection in an 8 month old-boy. Pediatr Pulmonol 1998; 25: 45-47.

49 Gill A. Bong lung: regular smokers of cannabis show relatively distinctive histologic changes that predispose to pneumothorax. Am J Surg Pathol 2005; 29: 980-982.
50 Hartman TE, Primack SL, Kang EY, et al. Disease progression in usual interstitial pneumonia: assessment with serial CT. Chest 1996; 110: 378-382.

51 Carrington CB, Gaensler EA, Coutu M, et al. Natural history and treated course of usual and desquamative interstitial pneumonia. N Engl J Med 1978; 298: 801-809.

52 Flusser G, Gurman G, Zirkin H, et al. Desquamative interstitial pneumonitis causing acute respiratory failure, responsive only to immunosuppressants. Respiration 1991; 58: 324-326.

53 Knyazhitskiy A, Masson RG, Corkey R, et al. Beneficial response to macrolide antibiotic in a patient with desquamative interstitial pneumonia refractory to corticosteroid therapy. Chest 2008; 134: 185-187.

54 Barberis M, Mazari S, Tironi A, et al. Recurrence of primary disease in a single lung transplant recipient. Transplant Proc 1992; 24: 2660-2662.

55 Verleden GM, Sels F, Van Raemdonck D, et al. Possible recurrence of desquamative interstitial pneumonitis in a single lung transplant recipient. Eur Respir J 1998; 11: 971-974. 